\title{
Are fiscal budgets sustainable in South Africa? Evidence from provincial level data
}

\author{
Kambale Kavase, ${ }^{1}$ Andrew Phiri ${ }^{2}$ \\ ${ }^{1}$ Faculty Eastern Cape Socio Economic Consultation Council, South Africa \\ ${ }^{2}$ Faculty of Business and Economic Studies, Nelson Mandela University, South Africa \\ corresponding e-mail: phiricandrew[at]gmail(dot)com \\ address: 16 Esselen Street, Cnr Esselen Street \& Steve Biko Avenue, Die Bult, Potchefstroom, 2531, South Africa
}

\begin{abstract}
This study uses the nonlinear autoregressive distributive lag (N-ARDL) model to investigate the expenditure-revenue relationship for all nine South African provinces using annual data spanning from 2000 to 2016. Whereas other cointegration models can only depict whether budgets are sustainable or not, the $\mathrm{N}$ ARDL model presents features which further enable us to predict a course of action which individual provincial governments can take towards attaining higher levels of budgetary sustainability in both the short and the long-run. Ultimately, our empirical study demonstrates that the 'one rule fit all' strategy as suggested by previous studies may not be an appropriate approach seeing that provincial governments have differing requirements for attaining improved levels of budget sustainability
\end{abstract}

JEL Classifications: C13, C32, H61, H72

Keywords: Fiscal expenditures, fiscal revenues, budget sustainability, South Africa

Citation: Kavase, K., \& Phiri, A. (2018). Are fiscal budgets sustainable in South Africa? Evidence from provincial level data. Business and Economic Horizons, 14(2), 415-423.

http://dx.doi.org/10.15208/beh.2018.30

\section{Introduction}

Since the advent of South Africa's democracy in 1994, the quest for all-inclusive growth, reducing poverty, inequality and unemployment through discretionary fiscal policy has been the cornerstone of most development policies. To attain these objective, South African government has implemented various large scale expenditure prorgammes, specifically, the Reconstruction and Development Program (RDP) in 1994; the Growth, Employment and Redistribution strategy (GEAR) in 1998; the Accelerated and Shared Growth Initiative for South Africa (AsgiSA) in 2004, the New Growth Path (NGP) in 2010 and most recently, the National Development Plan (NDP) in 2014. In order to raise the necessary revenues for the aforementioned fiscal expenditure programmes, taxation governing bodies like the Katz Commission and its successor the Davis Tax committee have been mandated by the ruling ANC government, the responsibility of ensuring the functionality and efficiency of tax revenues collection.

The economic meltdown of 2008/2009 has aggravated the persisting triple challenge of unemployment, poverty and low growth path with the economic crisis driving unemployment rate in South Africa to unprecedentedly high levels from $23 \%$ in 2008 , with 4.3 million people unemployed, to $26 \%$ in 2016 with 5.5 million people unemployed whereas GDP growth has simmered from $5.4 \%$ in 2006 to $0.3 \%$ in 2016 . At a fiscal level, the twin dilemma of high spending on social programs and constrained resources has resulted in the paradox of government trying to improve the lives of South African citizens through increased expenditure projects which, in turn, are financed by increased tax collections which eventually deteriorates the welfare of economic agents. Moreover, 
following the 2008 crisis, there has been an increasing gap between expenditure and revenues which has resulted in a widening budget deficit thus creating a hurdle which constrains economic development especially at provincial levels. This realization has prompted fiscal authorities to implement fiscal austerity measures as a means of attaining a sustainable budget over the steady-state.

In our paper we argue that the impact of such austerity practices on budget sustainability can be empirical evaluated through implementing appropriate econometric analysis. Even though previous studies have been conducted on the subject matter for South Africa (i.e. Narayan \& Nayaran, 2006; Nyamongo et al., 2006; Lusinyan \& Thornton, 2007; Ndahiriwe \& Gupta, 2010; Ghartey, 2010; Jibao et al., 2012; Baharumshah et al., 2016; and Phiri, 2017) we point out that these studies suffer some fundamental shortcomings. Firstlyt, a majority of these studies assume linearity in the cointegration analysis (i.e. Narayan \& Nayaran, 2006; Nyamongo et al., 2006; Lusinyan \& Thornton, 2007; Ndahiriwe \& Gupta, 2010; Ghartey, 2010; Jibao et al., 2012; Baharumshah et al., 2016) a feature which may be oversimplifying the issue (see Bajo-Rubio et al., 2006 and Ewing et al., 2006 for a discussion). Secondly, even when nonlinearity has been taken into consideration (i.e. Phiri, 2017)), such asymmetry is assumed to exist in the short-run whilst symmetry is retained over the long-run. Lastly, all previous studies focus on national aggregated data whilst ignoring the provincial specific relations. This later point has important policy implications since different provinces are faced with different budget constraints which may exhibit different levels of sustainability.

Our study contributes to the existing body of empirical literature for expenditure-revenues nexus by employing the recently introduced nonlinear autoregressive distributive lag $(\mathrm{N}$ ARDL) model of Shin et al. (2014) to South African provincial data collected between 2000 and 2006. To the very best of our knowledge, this becomes the first study to employ this econometric model to the expenditure-revenue relationship within the broader empirical literature. In differing from a host of other nonlinear cointegration models the $\mathrm{N}$-ARDL model presents functional advantages such as allowing the modelling of both short-run and long-run cointegration effects amongst a mixture of levels stationary and first difference stationary variables. Moreover, the N-ARDL model, on account of being an asymmetric extension of the ARDL model of Pesaran et al. (2001), performs exceptionally well even when the utilized time series spans over as short period. This last feature of the model enables us to perform our analysis using annual data collected over a relatively short period of 2000 to 2016.

Having provided a background to the study, the rest of the paper is arranged as follows. The following section presents the methodology of the paper, the third section of the paper presents the data and empirical results whereas the paper is concluded in the fourth section of the paper.

\section{Methodology}

\subsection{Theoretical framework}

In the spirit of Hakkio \& Rush (1991), we consider that the South African provincial governments' one period budget constraint is formulated as: 


$$
B_{t}=\left(G E_{t}+i B_{t-1}\right)-R_{t}
$$

Where $B_{t}$ is government debt, $G E_{t}$ is real government expenditure exclusive of interest payments, $R_{t}$ are real tax revenues and $i_{t}$ is the real interest rate which is assumed to be a stationary process around a mean of $i^{*}$. By defining $G_{t}=G E_{t}+\left(i_{t}-i^{*}\right) B_{t-1}$, and applying forward substitution results in the following intertemporal budget constraint:

$$
B_{0}=\Pi\left(R_{t+j+i}-G_{t+j+i}\right)+\lim _{j \rightarrow \infty} \Pi B_{t+j+i}
$$

Sustainability of a budget deficit occurs when:

$$
\lim _{j \rightarrow \infty} \Pi B_{t+j+i}=0
$$

That is when the current budget can be financed by future surpluses. Further considering that $i_{t} \sim I(0)$, and taking the first differences of equations (1) through (3), Quintos (1995) demonstrate that the following reduced-form long-run cointegration equation can be deduced:

$$
R_{t}=\alpha_{0}+\beta G_{t}+e_{t}
$$

Where $\alpha_{0}$ is regression intercept, $e_{t}$ is a well-behaved disturbance term and $\beta$ the long-run regression coefficient which is assumed a prior to positive and bounded between 0 and 1 . If $\beta=1$, then government deficit is high sustainable and reflects a highly efficient fiscal government which practices strict fiscal discipline. However, as $\beta$ approaches zero, then government debts becomes increasing unsustainable such that the intertemporal budget constraint (2) is less likely to hold. In such instances, government debt may be financed by raising interest rate to service debt obligations (Papeologou, 2013).

\subsection{N-ARDL model}

Using intuition provided by Shin et al. (2014), we suppose that $G_{t}$ can be decomposed into partial sum processes of positive and negative changes (i.e. $G_{t}=G_{0}+G_{t}^{+}+G_{t}^{-}$), such that equation (3) can be re-specified as the following long-run asymmetric model: 


$$
R_{t}=\alpha_{0}+\beta+G_{t}^{+}+\beta-G_{t}^{-}+e_{t}
$$

Where $G_{t}^{+}=\sum_{j=1}^{i} \Delta G_{j}^{+}=\sum_{j=1}^{i} \max \left(\Delta \mathrm{G}_{\mathrm{j}}, 0\right)$ and $G_{t}^{-}=\sum_{j=1}^{i} \Delta G_{j}^{-}=\sum_{j=1}^{i} \min \left(\Delta \mathrm{G}_{\mathrm{j}}\right.$, 0 ). The NARDL (p, q)-in-levels transformation of regression (4) can be given as:

$$
R_{t}=\sum_{j=1}^{p} \psi_{i} R_{t-j}+\sum_{j=1}^{p}\left(\Phi_{j}^{+} G_{t-j}^{+}+\Phi_{j}^{-} G_{t-j}^{-}\right)+\zeta_{t}
$$

Whereas the associated error correction representation can be denoted as:

$$
\begin{gathered}
R_{t}=\sum_{j=1}^{p} \rho_{i} R_{t-j}+\Phi_{j}^{+} G_{t-j}^{+}+\Phi_{j}^{-} G_{t-j}^{-}+\sum_{j=1}^{p-1} \lambda_{i} \Delta R_{t-j}+ \\
\sum_{j=0}^{q-1}\left(\alpha_{j}^{+} \Delta G_{t-j}^{+}+\alpha_{j}^{-} \Delta G_{t-j}^{-}\right)+\zeta_{t}
\end{gathered}
$$

The asymmetric long-run parameters of interest from equations 5 are thereafter computed as $\beta^{+}=-\left(\Phi^{+} / \rho\right)$ and $\beta^{-}=-\left(\Phi^{-} / \rho\right)$. To validate the NARDL long-run and shortrun effects, Shin et al. (2014) propose the testing of three empirical hypothesis. The first, is an asymmetric extension of the conventional bounds test for cointegration (Pesaran et al., 2001) and tests the null hypothesis of $\rho=\Phi^{+}=\Phi^{-}$. The second hypothesis tests the null of no long-run cointegration effects (i.e. $\beta^{-}=\beta^{+}$) whilst the third tests the null hypothesis of no short-run asymmetric effects (i.e. $\sum_{i=0}^{q-1} \alpha_{j}^{+}=\sum_{i=0}^{q-1} \alpha_{j}^{-}$).

\section{Data and empirical results}

\subsection{Data description}

The data used in our study has been collected from Quantec South Africa online statistical database. The time series is collected include total government expenditure (i.e. $G_{t}$ ) and the total government revenues (i.e. $R_{t}$ ) for all nine South Africa provinces (Western Cape, Eastern Cape, Northern Cape, Free State, Kwazulu-Natal, North West, Gauteng, Mpumalanga and Limpopo. All time series are collected on an annual basis frequency from 2000 to 2016 and both series are measured in their actual Rand values which are then converted into their natural logarithms. 


\subsection{Unit root test}

As previously mentioned, the N-ARDL model is fully operational with a mixture of levels stationary and first difference stationary variables. However, the model is not compatible with second difference stationary time series and therefore before any estimation can be made it is essential that we ensure that none of the time series is integrated of order $\mathrm{I}(2)$. To this end we perform the ADF, PP and DF-GLS unit root tests on the first differences of all observed time series and each test is conducted with i) an intercept and ii) a trend. The results of this empirical exercise are reported in Table 1 and, as can be observed all performed tests reject the null hypothesis of the time series being integrated of an order higher than I(1) at significance levels of at least 5 percent. In light of these results, we conclude that all the time series are suitable for N-ARDL modelling.

TABLE 1. UNIT ROOT TEST RESULTS ON SECOND DIFFERENCES ON TIME SERIES

\begin{tabular}{|c|c|c|c|c|c|c|c|}
\hline \multirow[t]{2}{*}{ PROVINCE } & \multirow{2}{*}{$\begin{array}{c}\text { TIME } \\
\text { SERIES }\end{array}$} & \multicolumn{2}{|c|}{$\mathrm{ADF}$} & \multicolumn{2}{|c|}{ PP } & \multicolumn{2}{|c|}{ DF-GLS } \\
\hline & & INTERCEPT & TREND & INTERCEPT & TREND & INTERCEPT & TREND \\
\hline \multirow[t]{2}{*}{ WC } & $G_{t}$ & $-4.77^{\star \star \star}$ & $-4.52^{\star \star \star}$ & $-6.32^{* * *}$ & $-6.01^{* * *}$ & $-4.88^{* * *}$ & $-4.94^{* * *}$ \\
\hline & $R_{t}$ & $-5.21^{* \star \star}$ & $-4.97^{\star \star *}$ & $-7.93^{\star \star \star}$ & $-7.66^{* * *}$ & $-5.36^{\star \star \star}$ & $-5.42^{\star * \star}$ \\
\hline \multirow[t]{2}{*}{ EC } & $G_{t}$ & $-5.51^{* \star \star}$ & $-5.30^{\star * \star}$ & $-11.19^{* \star *}$ & $-11.68^{* * *}$ & $-5.73^{\star \star \star}$ & $-5.76^{\star \star \star}$ \\
\hline & $R_{t}$ & $-5.38^{\star * *}$ & $-5.20^{* \star *}$ & $-10.15^{\star \star *}$ & $-11.10^{\star * \star}$ & $-5.59^{* * *}$ & $-5.64^{* \star \star}$ \\
\hline \multirow[t]{2}{*}{$\mathrm{NC}$} & $G_{t}$ & $-6.70^{\star \star *}$ & $-6.46^{* \star *}$ & $-14.03^{* \star *}$ & -14.93 & $-6.91^{* * *}$ & $-6.96^{* * *}$ \\
\hline & $R_{t}$ & $-5.74^{* \star \star}$ & $-5.53^{\star \star \star}$ & $-8.99^{\star \star \star}$ & $-11.31^{\star * \star}$ & $-5.93^{\star \star \star}$ & $-5.99^{* * \star}$ \\
\hline \multirow[t]{2}{*}{ FS } & $G_{t}$ & $-5.83^{\star \star \star}$ & $-5.69^{\star \star \star}$ & $-7.75^{\star \star \star}$ & $-10.26^{\star * \star}$ & $-6.05^{\star \star \star}$ & $-6.19^{* * \star}$ \\
\hline & $R_{t}$ & $-5.50^{\star \star \star}$ & $-5.31^{\star \star \star}$ & $-8.95^{\star \star \star}$ & $-10.95^{\star \star \star}$ & $-5.70^{\star \star \star}$ & $-5.75^{\star \star \star}$ \\
\hline \multirow[t]{2}{*}{ KZN } & $G_{t}$ & $-4.82^{\star \star \star}$ & $-4.62^{\star \star \star}$ & $-9.82^{\star \star \star}$ & $-9.69^{\star \star \star}$ & $-5.01^{\star \star \star}$ & $-5.02^{\star \star \star}$ \\
\hline & $R_{t}$ & $-4.79^{\star \star \star}$ & $-4.62^{\star \star \star}$ & $-7.83^{\star \star \star}$ & $-8.78^{\star * \star}$ & $-4.98^{\star \star \star}$ & $-5.02^{\star \star \star}$ \\
\hline \multirow[t]{2}{*}{ NW } & $G_{t}$ & $-4.67^{\star \star \star}$ & $-4.35^{\star \star \star}$ & $-19.52^{\star \star \star}$ & $-18.57^{\star * *}$ & $-4.88^{\star \star \star}$ & $-4.86^{\star \star \star}$ \\
\hline & $R_{t}$ & $-4.90^{* * *}$ & $-4.66^{\star \star \star}$ & $-18.74^{\star \star \star}$ & $-18.09^{\star * \star}$ & $-5.15^{\star \star \star}$ & $-5.04^{\star \star \star}$ \\
\hline \multirow[t]{2}{*}{ GP } & $G_{t}$ & $-5.23^{* * *}$ & $-5.04^{\star \star \star}$ & $-7.60^{* \star *}$ & $-7.03^{\star * *}$ & $-5.44^{\star \star \star}$ & $-5.48^{\star \star \star}$ \\
\hline & $R_{t}$ & $-6.16^{* \star \star}$ & $-5.88^{\star \star \star}$ & $-14.45^{\star * \star}$ & $-13.86^{\star * \star}$ & $-6.33^{\star \star *}$ & $-6.39^{* * *}$ \\
\hline \multirow[t]{2}{*}{ MPL } & $G_{t}$ & $-3.88^{* *}$ & $-3.72^{\star \star \star}$ & $-6.55^{\star \star \star}$ & $-6.22^{\star * *}$ & $-4.03^{\star \star \star}$ & $-4.04^{* * *}$ \\
\hline & $R_{t}$ & $-4.83^{\star \star *}$ & $-4.63^{* *}$ & $-9.21^{* * *}$ & $-9.28^{\star \star *}$ & $-5.02^{\star \star \star}$ & $-5.04^{\star * \star}$ \\
\hline \multirow[t]{2}{*}{ LIM } & $G_{t}$ & $-6.86^{* \star *}$ & $-6.57^{\star \star \star}$ & $-9.32^{\star \star \star}$ & $-10.74^{\star * *}$ & $-7.05^{\star \star \star}$ & $-7.12^{\star \star \star}$ \\
\hline & $R_{t}$ & $-5.62^{\star * *}$ & $-5.40^{\star * \star}$ & $-11.54^{\star \star *}$ & $-11.93^{* \star *}$ & $-5.84^{* * *}$ & $-5.87^{\star \star \star}$ \\
\hline
\end{tabular}

Note: "***', ‘**', ‘ ' denote the $1 \%, 5 \%$ and $10 \%$ critical levels respectively

\subsection{Empirical analysis}

Having assured that none of the time series variables is second difference stationary, we proceed to our formal empirical analysis we begins by reporting on the results obtained from the asymmetric cointegration tests as performed on our empirical N-ARDL regressions for all nine provinces. As shown in Table 2, we find extremely encouraging results in the sense that the test statistics produced for all three tested hypotheses reject the null hypotheses of i) no nonlinear ARDL effects ii) no long-run asymmetric effects and iii) no short-run asymmetric effects. We particularly note that all statistics manage to reject their respective null hypotheses at all levels of significance. This permits us to 
proceed to estimate the N-ARDL $(1,0,0)$ models for expenditure-revenue regression for all nine South African provinces.

TABLE 2. N-ARDL COINTEGRATION TESTS

\begin{tabular}{|c|c|c|c|}
\hline Province & $\rho=\Phi^{+}=\Phi$ & $\beta^{-}=\beta^{+}$ & $\sum_{i=0}^{q-1} \alpha_{j}^{+}=\sum_{i=0}^{q-1} \alpha_{j}^{-}$ \\
\hline WC & $17.96^{\star \star *}$ & $15.79^{* * *}$ & $19.74^{* * *}$ \\
\hline $\mathrm{EC}$ & $10.48^{\star * \star}$ & $8.22^{* * *}$ & $11.57^{* * *}$ \\
\hline $\mathrm{NC}$ & $13.00^{* * *}$ & $21.98^{* * *}$ & $16.64^{* * *}$ \\
\hline FS & $7.40^{* * *}$ & $10.73^{* * *}$ & $6.54^{* * *}$ \\
\hline KZN & $13.33^{\star \star \star}$ & $4.54^{\star \star \star}$ & $7.89^{\star \star \star}$ \\
\hline NW & $6.16^{\star \star \star}$ & $6.74^{\star * \star}$ & $7.56^{\star \star \star}$ \\
\hline GP & $22.59^{\star \star \star}$ & $4.28^{\star \star \star}$ & $5.46^{\star \star \star}$ \\
\hline MPL & $15.96^{\star \star \star}$ & $8.58^{\star \star \star}$ & $9.87^{\text {*** }}$ \\
\hline LIM & $6.49^{\star * *}$ & $14.32^{\star \star \star}$ & $10.32^{* \star *}$ \\
\hline
\end{tabular}

Before providing a discussion of our long-run and short-run regression estimates which are respectively reported in panels $\mathrm{A}$ and $\mathrm{B}$ of Table 3 , it is essential that we provide a brief description of the manner of interpreting the estimated coefficients. The positive and highly significant coefficient estimates associated with $G^{+}\left(\Delta G^{+}\right)$and the $G^{-}\left(\Delta G^{-}\right)$ variables, implies that increase in government expenditure are associated with increasers in government revenues whilst decrease in expenditure are accompanied by decreases in revenues collection. Recall, from the earlier discussion of the study's theoretical underpinnings, higher coefficient estimates imply higher levels of budgetary sustainability. Therefore, when $G^{+}\left(\Delta G^{+}\right)>G^{-}\left(\Delta G^{-}\right)$, then increased government expenditures and revenues would result in higher levels of budget sustainability. Conversely when $G^{+}\left(\Delta G^{+}\right)$ $<G^{-}\left(\Delta G^{-}\right)$, then decreases in expenditure and revenues would ensure increased budget sustainability.

Therefore in collectively summarizing our findings, we firstly note that over the long-run, as shown in Panel A of Table 3, the Eastern Cape, Norther Cape, Free-Sate and KwaZulu-Natal provinces would exert higher levels of budget sustainability by increasing government expenditure and revenues since the estimated coefficients satisfy the condition $G^{+}>G^{-}$. Conversely, for the remaining provinces where $G^{+}<G^{-}$(i.e. Western Cape, North West, Gauteng, Mpumalanga and Limpopo), higher budgetary sustainability can be attained by lowering expenditures and revenues.

Moreover, we also point out that the Western Cape, North West, Gauteng and Mpumalanga and Limpopo provinces have extremely efficient budgets in the long-run, since the coefficient values of both $G^{+}$and $G^{-}$produce values equal to or greater than unity. These 'above-unity' estimates are not strange findings since our estimation timeframe covers a period where most provincial governments recorded surpluses in their respective budgets (i.e. fiscal year of 2005/2006 and 2006/2007). On the other hand, the Eastern Cape, Northern Cape, Free-State and KwaZulu-Natal appear to be the provinces with the least sustainable budgets as at least one of the $G^{+}$or $G^{-}$coefficients produces values less than unity. However, we are quick to point out that for the cases of the Eastern Cape and KwaZulu-Natal provinces, the $G^{+}$values are equal to or exceed unity, hence 
implying that complete budget sustainability can be achieved in theses provinces conditional that local governments increase expenditures and revenues in these provinces. Nevertheless, for the case of the Northern Cape and Free-State provinces, complete budget sustainability cannot be attained since neither $G^{+}$nor $G^{-}$estimates exceeds unity.

\section{TABLE 3. N-ARDL ESTIMATES}

\begin{tabular}{|c|c|c|c|c|c|c|c|c|c|}
\hline & WC & $\mathrm{EC}$ & $\mathrm{NC}$ & FS & $\mathrm{KZN}$ & NW & GP & MPL & LIM \\
\hline \multicolumn{10}{|c|}{ PANEL A: LONG-RUN ESTIMATES } \\
\hline \multirow{2}{*}{$G^{+}$} & 1.03 & 1.04 & 0.99 & 0.98 & 1.00 & 1.02 & 1.11 & 1.00 & 1.06 \\
\hline & $(0.00)^{\star * *}$ & $(0.00)^{* *}$ & $(0.00)^{\star \star \star *}$ & $(0.00)^{\star * *}$ & $(0.00)^{\star * *}$ & $(0.00)^{* * *}$ & $(0.00)^{* * *}$ & $(0.00)^{\star \star *}$ & $(0.00)^{* * *}$ \\
\hline \multirow[t]{2}{*}{$G^{-}$} & 1.51 & 0.74 & 0.64 & 0.85 & 0.96 & 1.14 & 1.77 & 1.17 & 1.08 \\
\hline & $(0.00)^{\star * *}$ & $(0.00)^{\star \star \star}$ & $(0.00)^{\star \star * \star}$ & $(0.00)^{\star \star *}$ & $(0.00)^{\star * *}$ & $(0.00)^{\star \star \star}$ & $(0.00)^{\star \star \star}$ & $(0.00)^{\star \star \star *}$ & $(0.00)^{\star \star \star}$ \\
\hline \multicolumn{10}{|c|}{ PANEL B: SHORT RUN ESTIMATES } \\
\hline \multirow[t]{2}{*}{$\Delta G^{+}$} & 1.01 & 0.74 & 0.93 & 1.07 & 0.88 & 0.91 & 0.72 & 1.00 & 0.90 \\
\hline & $(0.00)^{\star * *}$ & $(0.00)^{\star \star *}$ & $(0.00)^{\star \star}$ & $(0.00)^{\star * *}$ & $(0.00)^{* * *}$ & $(0.00)^{\star \star *}$ & $(0.00)^{* \star *}$ & $(0.00)^{\star * *}$ & $(0.00)^{* * *}$ \\
\hline \multirow[t]{2}{*}{$\Delta G^{-}$} & 1.49 & 0.68 & 0.71 & -0.79 & 1.07 & 1.33 & 1.63 & 1.27 & 1.16 \\
\hline & $(0.00)^{\star * *}$ & $(0.00)^{\star \star \star}$ & $(0.00)^{\star \star *}$ & $(0.00)^{\star *}$ & $(0.00)^{\star * *}$ & $(0.00)^{* \star *}$ & $(0.00)^{\star \star \star}$ & $(0.00)^{\star \star *}$ & $(0.00)^{* \star \star}$ \\
\hline \multirow{2}{*}{$e c t_{t-1}$} & -0.94 & -0.79 & -0.96 & -0.99 & -0.91 & -0.75 & -0.64 & -0.90 & -0.98 \\
\hline & $(0.01)^{\star *}$ & $(0.00)^{* * *}$ & $(0.00)^{\star \star *}$ & $(0.00)^{\star \star *}$ & $(0.00)^{\star \star *}$ & $(0.00)^{\star \star *}$ & $(0.00)^{\star * *}$ & $(0.00)^{\star \star \star *}$ & $(0.00)^{\star \star \star}$ \\
\hline \multicolumn{10}{|c|}{ PANEL C: DIAGNOSTIC TESTS } \\
\hline \multirow{2}{*}{$\chi_{N O R M}^{2}$} & 1.27 & 0.99 & 2.40 & 5.34 & 21.11 & 0.14 & 0.27 & 0.73 & 0.26 \\
\hline & $(0.53)$ & $(0.61)$ & $(0.30)$ & $(0.07)$ & $(0.00)$ & $(0.93)$ & $(0.87)$ & $(0.69)$ & $(0.87)$ \\
\hline \multirow{2}{*}{$\chi_{S C}^{2}$} & 0.87 & 0.62 & 0.07 & 1.89 & 0.37 & 1.24 & 2.85 & 0.23 & 0.93 \\
\hline & $(0.45)$ & $(0.56)$ & $(0.94)$ & $(0.20)$ & $(0.70)$ & $(0.33)$ & $(0.11)$ & $(0.80)$ & $(0.43)$ \\
\hline \multirow{2}{*}{$\chi_{H E T}^{2}$} & 2.39 & 0.01 & 0.40 & 0.04 & 0.08 & 8.58 & 1.72 & 0.01 & 0.03 \\
\hline & $(0.15)$ & $(0.98)$ & $(0.54)$ & $(0.85)$ & $(0.78)$ & $(0.01)$ & $(0.21)$ & $(0.96)$ & $(0.86)$ \\
\hline \multirow[t]{2}{*}{$\chi_{F F}^{2}$} & 0.76 & 0.63 & 3.85 & 1.46 & 2.21 & 2.87 & 0.30 & 0.75 & 1.18 \\
\hline & $(0.46)$ & $(0.54)$ & $(0.00)$ & $(0.17)$ & $(0.05)$ & $(0.02)$ & $(0.77)$ & $(0.47)$ & $(0.26)$ \\
\hline
\end{tabular}

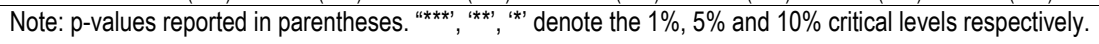

In turning our focus towards the short-run dynamics, as reported in Panel B of Table 3, we firstly note that short-term budgets can be improved by reducing expenditure and revenues in the Western Cape, KwaZulu-Natal, North West, Gauteng, Mpumalanga and Limpopo provinces. Conversely, short-term budgets in the Eastern Cape, Northern Cape and Free-State provinces can be improved by increasing short-term expenditures and revenues. We also observe short-term complete budget sustainability only for the Western ape and Mpumalanga data since both $\Delta G^{+}$and $\Delta G^{-}$produce values which exceed unity for these provinces. On the other hand, we note that short-term budgets in the Eastern Cape and Northern Cape cannot achieve complete budget sustainability regardless of decrease or increase in expenditures and revenues since the values on the $\Delta G^{+}$and $\Delta G^{-}$ variables are both lower than unity.

We further observe that the error correction terms, which provide a measure of the speed of adjustment back to equilibrium subsequent to a shock to the economy, all produce significant estimates which are of the correct negative values. However, the speed of adjustment differs for each province, with the Free-State having the highest adjustment speed at 99 percent per annum followed by Limpopo (98 percent), Northern Cape (96 percent), Western Cape (94 percent), KwaZulu-Natal (91 percent), Mpumalanga (90 percent), Eastern Cape (79 percent), North West (75 percent) and Gauteng (64 percent). 
AS the last step in our empirical analysis, we perform diagnostic tests for the estimated regressions. We particularly test for normality, serial correlation, heteroscedasticity and functional form with the results of these tests being reported in Panel C of Table 3. As can be easily observed none of the extracted errors from our estimated N-ARDL regressions suffers from non-normality, autocorrelation and heteroscedasticity. Moreover, none of the estimated regression is of an incorrect functional form. Collectively, this presents sufficient evidence that all estimated N-ARDL models conform to the conditions stipulated under the classical regressions model assumptions and hence our estimations can be interpreted with non-spurious meaning.

\section{Conclusions}

This study has taken a different empirical approach to analysing the expenditure-revenue nexus for the South African economic by examining the relationship from a provincial perspective using annual data collected between 2000 and 2016. Our mode of empirical investigating is the N-ARDL model of Shin et al. (2016) which contains a unique feature of identifying whether increase or decreases in provincial budgets will improve or deteriorate the ability of provincial government authorities to sustain their respective budgets. In this sense, the model is able to identify which provinces need to increase their expenditure-revenue budgets and which provinces need to reduce their budgets.

Our empirical results specifically imply that over the long-run, the Eastern Cape, Norther Cape, Free-Sate and KwaZulu-Natal provinces should reduce their budgets to attain greater budget sustainability whereas, Western Cape, North West, Gauteng, Mpumalanga and Limpopo provinces need to lower their expenditure-revenue budgets in order to be more sustainable over the long-run. However, over the short-run, Eastern Cape, Northern Cape and Free-State provinces need to increase their budgets to attain higher levels of sustainability whereas Western Cape, KwaZulu-Natal, North West, Gauteng, Mpumalanga and Limpopo provinces are advised to decrease their budgets in order to be more sustainable. Overall, the 'one-rule-fit-all' strategy as suggested by previous South African studies provides limited information towards provincial governments as these provinces require different strategies in improving the sustainability of their respective budgets.

\section{References}

Baharumshah, A., Jibrilla, A., Sirag, A., Ali, H., \& Muhammad, I. (2016). Public revenueexpenditure nexus in South Africa: Are there asymmetries. South African Journal of Economics, 84(4), 520-537.

Bajo-Rubio, O., Diaz-Roldan, C., \& Esteve, V. (2006). Is the budget deficit sustainable when fiscal policy is nonlinear? The case of Spain. Journal of Macroeconomics, 28, 596-608.

Ewing, B., Payne, J., Thompson, M., \& Al-Zoubi, O. (2006). Government expenditures and revenues: Evidence from asymmetric modelling. Southern Economic Journal, 73, 190-200.

Ghartey, E. (2010). Cointegration and causal relationship between taxes and spending in Kenya, Nigeria and South Africa. International Economic Journal, 24(2), 267-282.

Haikko, C. \& Rush, M. (1991). Is the budget deficit ‘Too Large’? Economic Inquiry, 29, 99-126. 
Jibao, S., Schoeman, \& Naraidoo, R. (2012). Fiscal regime changes and the sustainability of fiscal imbalance in South Africa: A smooth transition error-correction approach. South African Journal of Economic and Management Sciences, 15(2), 112-127.

Lusinyan, L., \& Thornton, J. (2007). The revenue-expenditure nexus: Historical evidence for South Africa. South African Journal of Economics, 75, 496-507.

Narayan, P., \& Narayan, S. (2006). Government revenue and government expenditure nexus: Evidence from developing countries. Applied Economics, 38(3), 285-291.

Ndahiriwe, K., \& Gupta, R. (2010). Temporal causality between taxes and public expenditures: The case of South Africa. The Journal of World Economic Review, 6(1), 87-100.

Nyamongo, M., Sichei, M., \& Schoeman, N. (2007) .Government revenue and expenditure nexus in South Africa. South African Journal of Economic and Management Sciences, 10(2), 256-268.

Paleologou, S. (2013). Asymmetries in the revenue-expenditure nexus: A tale of three countries. Economic Modelling, 30, 52-60.

Pesaran, M., Shin, Y., \& Smith, R. (2001). Bounds testing approaches to the analysis of level relationships. Journal of Econometrics, 16(3), 289-326.

Phiri, A. (2017). Asymmetries in the revenue-expenditure nexus: New evidence from South Africa. Empirical Economics, 2017. https://doi.org/10.1007/s00181-017-1397-0

Quintos, C. (1995). Sustainability of the deficit process with structural shifts. Journal of Business and Economic Statistics, 13(4), 409-417.

Shin, Y., Yu B., \& Greenwood-Nimmo, M. (2014). Modelling asymmetric cointegration and dynamic multipliers in a nonlinear ARDL framework. In R. Sickels and W. Horace Festsschrift (Eds.). In honor of Peter Schmidt: Econometric Methods and Applications (pp.281-314). Springer. 